\title{
Het sensatiegehalte van voorpaginafoto's: een inhoudsanalyse van populaire en kwaliteitskranten in Nederland
}

Een kwantitatieve inhoudsanalyse van foto's in 'kwaliteitskranten' en 'populaire kranten' op aspecten van sensatie laat zien dat een meerderheid van de foto's op de voorpagina's van Nederlandse kranten een sensationeel onderwerp bevat. Een kwart tot een derde van de foto's heeft een sensationele vormgeving. Op acht van de elf sensatiekenmerken zijn foto's in populaire kranten sensationeler dan die in kwaliteitskranten. Echter, in sommige gevallen zijn de verschillen binnen de twee groepen groter dan die ertussen.

\section{Introductie}

Het verschijnsel 'sensatie in het nieuws' kan zich de laatste jaren verheugen op een groeiende maatschappelijke en wetenschappelijke belangstelling. Kern van het debat over sensatie is de versmelting van informatie en entertainment; critici vrezen dat sensatie steeds meer de plaats van 'echte' informatie zal innemen, niet alleen doordat steeds meer van de beperkte tijd en ruimte in de nieuwsmedia besteed zal worden aan onder andere human interest, drama en emoties, en niet aan 'serieuze' informatie, maar ook doordat de twee steeds meer versmelten tot 'infotainment'. De aandacht en interesse van het publiek lijkt vooral te liggen bij sensationele berichtgeving (Grabe, Lang \& Zhao, 2003; Tai \& Chang, 2002). Men vreest dat het gevolg daarvan is dat de burger onvoldoende geïnformeerd wordt over zaken die er in een democratisch bestel werkelijk toe doen.

Zowel in Europa als in de Verenigde Staten is de afgelopen vijftien jaar veel onderzoek gedaan naar sensatie in het nieuws en de effecten ervan op de ontvanger (Djupsund \& Carlson, I998; Grabe, Lang \& Zhao, 2003; Grabe, Zhou, Lang \& Bolls, 2000; Hendriks Vettehen, Nuijten \& Beentjes, 2005; Hendriks Vettehen \& Nuijten, 2006; Hjarvard, 2000; Hvitfelt, I994; Kleemans, Van Cauwenberge, d'Haenens \& Hendriks Vettehen, 2008; Slattery \& Hakanen, I994; Uribe \& Gunter, 2004). Dit

* Dr. Gabi Schaap is docent aan de Radboud Universiteit Nijmegen. Contactgegevens: Thomas van Aquinostraat 2, 6500 HE Nijmegen, 024-36II793, g.schaap@maw.ru.nl.

Dr. Alexander Pleijter is universitair docent aan de Rijksuniversiteit Groningen. Contactgegevens: Oude Kijk in 't Jatstraat 26, 9712 EK Groningen, o6-30296989, a.r.j.pleijter@rug.nl. 
onderzoek toont aan dat er sprake is van een trend naar sensatie in het nieuws in verschillende landen, zowel bij de schrijvende pers als bij televisienieuws.

De effecten van sensatie zijn niet eenduidig positief of negatief. Enerzijds zorgt een vleugje sensatie in een nieuwsitem er bijvoorbeeld voor dat kijkers met meer aandacht naar het nieuws kijken, en dat ze zich daardoor meer van het nieuws herinneren. Anderzijds zorgt een teveel aan sensatie ervoor dat de aandacht te veel wordt getrokken door de sensationele aspecten van een nieuwsitem, terwijl de inhoud ondergesneeuwd raakt (Grabe et al., 2003).

De toename van sensatie wordt vaak toegeschreven aan een toenemende concurrentie en commercialisering op de nieuwsmarkt (Esser, I999; Graber, I994; Kleemans, Van Cauwenberge, d'Haenens \& Hendriks Vettehen, 2008; Lewis, Andrews \& Franklin, 2008; McManus, 2009; Mindich, 2005). Hoewel de daling in lezerspubliek al sinds de jaren zeventig aan de gang is, zitten met name kranten de laatste twee decennia in zwaar weer, met stelselmatig dalende oplagen en dalend bereik in vrijwel alle westerse landen (Huysmans, De Haan \& Van den Broek, 2005; Pew, 2008; Raeymaeckers, 2002; Schönbach, Lauf, McLeod \& Scheufele, I999). Waar landelijke en regionale (betaalde) dagbladen in I986 nog op een bereik van 73 procent konden rekenen, is dat in 20 Io gedaald tot iets meer dan zestig procent van de bevolking van I3 jaar en ouder (Cebuco, I992; NOM, 2008). Vooral het laatste decennium heeft de daling sterk ingezet: in de periode $200 \mathrm{I}-2009$ zo'n tien procent oplagedaling in Nederland. De daling lijkt vooral veroorzaakt doordat de jongste lezersgroep sterk afneemt (Raeymaeckers, 2002). In 2005 is van iedereen boven de 35 jaar meer dan vijftig procent regelmatige krantenlezer, van iedereen onder 35 is dat maar een derde of nog minder, bovendien besteedt deze groep veel minder tijd aan het lezen van de krant (Huysmans, De Haan \& Van den Broek, 2005).

De slag om abonnee en adverteerder zorgt ervoor dat het steeds belangrijker wordt de krant aantrekkelijk te maken en de aandacht te trekken van het publiek. Naast zaken als nieuwe formats, bijlagen en lezersaanbiedingen, is de foto een belangrijk middel om die aandacht te trekken. Met name de voorpaginafoto wordt gezien als het visitekaartje van de krant, die een potentiële koper moet aanzetten een krant aan te schaffen. Uit eye-trackingonderzoek blijkt dat de foto inderdaad de eerste blikvanger is op de voorpagina's van kranten - in tegenstelling tot foto's op websites overigens (Garcia \& Stark, I99I; Outing, 2004). Men begint het lezen van de krant met het kijken naar de foto('s) op de voorpagina en als tweede met het lezen van de onderschriften bij de foto's, daarna volgen de koppen en ten slotte pas gaat men (een deel van) de berichten lezen. Krantenfoto's bepalen ook of en hoe intensief een bericht gelezen wordt (Knobloch, Hastall, Zillmann \& Callison, 2003; Zillmann, Knobloch \& Yu, 200I). Een bericht met een foto maakt grotere kans om gelezen te worden dan een bericht zonder foto; een bericht met een sensationele foto op zijn beurt nog meer dan een bericht met een gewone foto. Ook worden berichten met sensationele foto's langer gelezen dan berichten met gewone foto's en zonder foto's. Ook beïnvloeden foto's of en in welke mate men geneigd is na te denken over een kwestie en de mate van moreel redeneren (Coleman, 2006). 
Er is al onderzoek gedaan naar sensatie in nieuws op televisie en in mindere mate naar de inhoud van krantenberichten. Maar nog niet eerder is er kwantitatief onderzoek gedaan naar het sensatiegehalte van krantenfoto's. Dit leidt tot de onderzoeksvraag: in hoeverre zijn foto's in Nederlandse kranten sensationeel? En is er in dat opzicht een verschil tussen de 'kwaliteitskranten' en de 'populaire' kranten?

\section{Theorie}

Hoewel sensatie het maatschappelijk debat al bezighoudt sinds de moderne krant bestaat - dat wil zeggen vanaf op zijn laatst het eind van de negentiende eeuw met de opkomst van 'yellow journalism' in de Verenigde Staten - is het vinden van een wetenschappelijk bruikbare definitie niet eenvoudig. Dit heeft grotendeels te maken met het feit dat de discussie ook in de wetenschap vaak een sterke normatieve lading heeft. Deze discussie is op diverse plaatsen reeds uitvoerig beschreven (o.a. Connel, I998; Grabe, Zhou \& Barnett, 200I; Hauttekeete, 2005; Nuijten, 2007). Sensatie wordt door het overgrote deel van de auteurs als iets 'slechts' beschouwd. Als ze sensatie (of het veelgebruikte equivalent 'tabloidisatie') definiëren, spreken ze bijvoorbeeld van een 'drop in professional standards' en een 'worsening of journalistic behavior' (Esser, I999, p. 299). Dit leidt tot 'trivialisatie' en 'visualisatie', waarbij het ideaal is dat beide zo weinig mogelijk in de serieuze pers voorkomen (Djupsund \& Carlson, I998). Een deel van de auteurs richt de blik vooral op de inhoudelijke aspecten van het nieuws (vgl. Adams, ı978; Connel, ı998; Slattery \& Hakanen, I994). Onderwerpen in het nieuws worden volgens hen 'softer' (entertainment, human interest, beroemdheden, sport, lifestyle en hobby's in plaats van 'hard' nieuws als politiek, economie en wetenschap) en dramatischer (geweld, seks, ongelukken en rampen). Het 'sensationele' vervangt het 'rationele': 'feitelijke rapportages' verworden tot 'emotionele verhalen' (Connel, I998). Naast inhoudelijke aspecten heeft een aantal auteurs zich ook beziggehouden met sensatie in termen van formele boodschapskenmerken, zoals het gebruik van beelden, of, in het geval van televisienieuws, cameratechnieken (Grabe, Zhou \& Barnett, 200I). Het probleem met al deze definities is dat moeilijk empirisch, dat wil zeggen 'objectief, vast te stellen is wat 'sensationeel' nieuws is en wat niet (Hendriks Vettehen et al., 2005). Daarnaast wordt niet altijd zowel de (sensationele) inhoud als de vorm in het onderzoek betrokken (Grabe et al., 200I).

Recent hebben wetenschappers daarom getracht sensatie vanuit een empirischwetenschappelijk uitgangspunt te definiëren en operationaliseren (cf. Grabe et al., 200I, 2003; Hendriks Vettehen et al., 2005). Uitgangspunt van wat inmiddels een bescheiden onderzoekstraditie genoemd mag worden, is het Limited Capacity Model for Mediated Message Processing (Lang, 2000). Sensatie wordt met behulp van deze theorie over informatieverwerking gedefinieerd aan de hand van het effect dat zowel vorm- als inhoudsaspecten van mediaboodschappen hebben op het cognitieve systeem van de ontvanger. Receptie van nieuws wordt in dit model gezien als 
het verwerken van informatie. Informatieverwerking gebeurt grotendeels gecontroleerd, dat wil zeggen dat de ontvanger zelf controle heeft over op welke (delen van een) mediaboodschap de aandacht wordt gericht en hoe intensief de boodschap wordt verwerkt. Een deel van de informatieverwerking gebeurt echter automatisch. Buiten de controle van de ontvanger om kunnen aspecten van een boodschap ervoor zorgen dat informatieverwerkingsprocessen in gang worden gezet. Dergelijke boodschapskenmerken zijn in staat psychologische en fysiologische opwinding ('arousal') te veroorzaken en aandacht ('attention') te trekken. Gecombineerd zorgen opwinding en aandacht voor een grotere mate van focus van het cognitieve systeem op een (deel van een) boodschap.

Sensatie is in deze zin vorm en inhoud die opwindt en die de aandacht trekt. Opwinding en aandacht zijn psychologische mechanismen die door sommige stimuli automatisch opgewekt kunnen worden en dus min of meer algemeen geldend zijn (Lang, 2000). Het centrale concept is daarbij overlevingswaarde: om te kunnen overleven zijn mensen cultureel en evolutionair gepredispositioneerd om automatisch signalen op te merken die op gevaar danwel een kans op overleving of voortplanting kunnen duiden (Bucey \& Bradley, 2004; Davis \& McLeod, 2003; Shoemaker, I996). De mens als organisme dient voortdurend zijn omgeving af te tasten en een passende reactie ('vlucht' of 'vecht'?) te ontwerpen. Vroeger ging het daarbij om daadwerkelijke levensbedreigingen en levenskansen (is dat een sabeltandtijger waar ik voor moet vluchten of een antilope die ik moet bejagen?), tegenwoordig bestaan dezelfde mechanismen nog steeds en kunnen ze worden opgewekt door de media (Newhagen, I998): bij sommige mediale inhouds- en vormaspecten wordt het menselijk brein automatisch in 'staat van paraatheid' gebracht.

Het Limited Capacity Model onderscheidt twee categorieën stimuli die deze 'orienting response' opwekken (Hendriks Vettehen et al., 2005, 2006): I. 'arousing content': inhoud die 'overlevingswaarde' heeft in evolutionaire zin. Dit zijn met name stimuli die refereren aan voortplanting en (bedreiging van) fysieke veiligheid, zoals geweld, rampen en seks (Lang, 2000). 2. 'tabloid packaging': vormaspecten die nieuwigheid ('novelty') of verandering benadrukken. Onverwachte of nieuwe zaken in onze omgeving duiden op verandering die onze aandacht behoeft, aangezien verandering kan duiden op gevaar of kansen. Veranderingen zijn daarom in staat een 'orienting response' op te roepen. Naast deze twee categorieën stimuli die appelleren aan overlevingswaarde, is in verder onderzoek een derde categorie stimuli die een 'orienting response' kunnen oproepen toegevoegd (Hendriks Vetehen et al., 2005, 2006). Het betreft stimuli die door hun levendigheid ('vividness') in staat zijn een automatische, aandachttrekkende reactie op te wekken. In sensatieonderzoek wordt onder levendigheid verstaan: boodschappen die concreet en nabij zijn. Volgens Nisbett en Ross (I980) hebben vormaspecten die nabijheid of concreetheid benadrukken de potentie om sterk de aandacht te trekken. Iets wat dichtbij of concreet is, is eerder een potentiële bedreiging of overlevingskans en verdient dus onze aandacht. Door de sterkere focus van de ontvanger op de boodschap worden levendige boodschappen beter onthouden en beïnvloeden ze sterker dan min- 
der levendige boodschappen het beoordelingsvermogen. Concrete (dat wil zeggen niet-abstracte of algemene) boodschappen bevatten concrete details over personen, situaties, etc. Onder nabijheid wordt zowel ruimtelijke/fysieke als temporele en zintuiglijke nabijheid verstaan. Zo worden gepersonaliseerde nieuwsberichten en nieuwsberichten die betrekking hebben op het eigen land, gezien als levendiger dan berichten die onpersoonlijk zijn of verslag doen van een gebeurtenis uit het buitenland (Hendriks Vettehen et al., 2005, 2006; Nuijten, 2007). Van alle bovenstaande aspecten is in onderzoek aangetoond dat ze een 'orienting response' veroorzaken; dat wil zeggen dat ze zowel emotionele prikkeling ('arousal') als cognitieve aandacht ('attention') opwekken (cf. Grabe et al., 2003). Sensatie omvat in deze definitie kenmerken van het nieuws die deze automatische respons veroorzaken. Het concept is eerder gebruikt in onderzoek naar het veranderende sensatiegehalte in het Nederlandse televisienieuws (Hendriks Vettehen et al., 2005; Nuijten, 2007). Wij volgen zo veel mogelijk deze conceptualisatie alsook de operationalisatie van het begrip sensatie om te onderzoeken hoe sensatie in Nederlandse dagbladfoto's voorkomt.

\section{Hypothesen}

Aangezien de markt voor kranten al jaren een sterk concurrerend speelveld is, worden kranten gedwongen met alle beschikbare middelen krantenlezers te trekken. Een van die middelen is het gebruiken van sensationele voorpaginafoto's. In landen buiten Nederland (Zweden, Finland en Groot-Brittannië) is aangetoond dat de berichtgeving in kranten de afgelopen decennia sensationeler geworden is (Djupsund \& Carlson, I998; Uribe \& Gunter, 2004). Ook weten we dat het Nederlandse televisienieuws sinds de jaren tachtig sensationeler geworden is (Nuijten, 2007). Bovendien is er sprake van een 'opmars van het beeld' in de krantenwereld: onder invloed van culturele veranderingen en technologische vooruitgang is het beeld een steeds prominentere plaats gaan innemen op de dagbladpagina (Broersma, 2003). Hoewel ze geen significantietoetsen rapporteren, stellen Zweedse onderzoekers naast een hoog percentage foto's in Zweden en Finland, een sterke toename vast in Finland van het aantal krantenfoto's op de voorpagina. Verder werden zowel in Zweden als in Finland voorpaginafoto's in de afgelopen decennia steeds groter (Djupsund \& Carlson, I998). Djupsund en Carlson stellen dat er een duidelijke trend is onder redacteuren om vaker te kiezen voor grotere, meer levendige en ‘expliciete' foto's (vgl. McManus, I994). Onze eerste hypothese luidt dan ook:

Hı: Het merendeel van de voorpaginafoto's in Nederlandse landelijke dagbladen bevat sensationele kenmerken.

In het maatschappelijk debat (o.a. door de journalistieke beroepsgroep zelf) en in wetenschappelijke literatuur wordt vaak onderscheid gemaakt tussen populaire kranten en kwaliteitskranten (Bakker \& Scholten, 2006; Jansen, I987; Lindhout \& Van Praag, 2000; Manssens \& Walgrave, I998). Populaire kranten zouden zich primair richten op een zo groot mogelijk publiek en brengen daarom meer 'soft' 
nieuws en de meer sensationele aspecten van 'serieus' nieuws (Ohlemacher, I996; Plasser \& Ulram, 2003). Kwaliteitskranten zouden zich daarentegen vooral bezighouden met hun publieke verantwoordelijkheid, het informeren van betrokken burgers, en plaatsen daarom meer 'serieus' of 'hard' nieuws, zoals politiek (Kleinnijenhuis, Oegema, De Ridder \& Van Hoof, 2007; Scholten \& Ruigrok, 2006). De verschillende dagbladtypen trekken daardoor ook verschillend lezerspubliek, wat betreft leeftijd, opleiding, welstand en interesses (NOM, 2008).

We weten uit onderzoek naar televisienieuws dat vergelijkbare 'populaire' nieuwsprogramma's inderdaad sensationeler zijn dan meer als 'serieus' beschouwde tegenhangers. Zo blijkt uit inhoudsanalyses dat het NOS-journaal minder sensationele kenmerken bevat dan het nieuwsprogramma van 'volkszender' SBS-6 (Nuijten, 2007). Het idee is daarom in het algemeen debat dat er een duidelijk zwart-witonderscheid gemaakt kan worden tussen de goede serieuze pers die mensen informeert en de misschien wel populaire maar toch veel minder het algemeen nut dienende pers (Van Hoof, 2000). Hoewel dit normatieve onderscheid ook door de beroepsgroep zelf routinematig gemaakt wordt, blijft het de vraag of het ook empirisch hard te maken is (Bakker \& Scholten, 2006; Connel, I998; Manssens \& Walgrave, I998; Van Hoof, 2000). Sommige auteurs beweren dat het onderscheid nooit bestaan heeft, of dat indien dat wel ooit het geval was is, het nu in rap tempo aan het verdwijnen is (Bakker \& Scholten, 2006; Connel, I998). In dit onderzoek willen we een bijdrage leveren aan deze discussie.

Op basis van aanwijzingen in bovenstaand onderzoek komen we tot de volgende hypothese:

H2: Voorpaginafoto's van populaire kranten bevatten meer sensationele kenmerken dan die van kwaliteitskranten.

\section{Methoden}

We hebben een kwantitatieve inhoudsanalyse gedaan op foto's van de voorpagina's van de vijf grootste landelijke kranten in Nederland. Hierbij werden (veronderstelde) kwaliteitskranten met populaire kranten vergeleken op het voorkomen van foto's met sensationele onderwerpen en vormaspecten.

\section{Eenheden}

Van september tot november 2005 werden voorpagina's verzameld op alle dagen van de week van de 'kwaliteitskranten' NRC Handelsblad, de Volkskrant en Trouw en van de 'populaire kranten' Algemeen Dagblad en De Telegraaf (Bakker \& Scholten, 2006). Codeereenheid was de krantenfoto. Van elke voorpagina werden krantenfoto's gecodeerd op alle kenmerken van sensatie, uitgezonderd foto's in advertenties en foto's in boven-, onder- en zijkolommen die fungeerden als zogenaamde 'ankei- 
lers' voor artikelen verderop in de krant. Met andere woorden, alle foto's in de 'main body' van de voorpagina werden in de analyse meegenomen $(N=427)$.

\section{Operationalisatie}

De operationalisatie volgde eerdere operationalisaties die gebruikt zijn bij inhoudsanalyse van sensatie in het Nederlandse televisienieuws (Hendriks Vettehen et al., 2005; Nuijten, 2007), met de nodige aanpassingen om het meetinstrument geschikt te maken voor de analyse van krantenfoto's. Dat wil zeggen dat elke foto werd gecodeerd op elf kenmerken van sensatie. Elk van die kenmerken is terug te voeren op een van de drie bovengenoemde dimensies van sensatie ('arousing content', 'tabloid packaging' en 'vividness'). Van deze dimensies is aangetoond dat ze een aandachttrekkende 'orienting response' tot gevolg hebben. We willen benadrukken dat het niet zo is dat een indicator an sich bepaalt of een foto sensationeel is of niet. De verschillende indicatoren vullen elkaar aan: een niet-sensationeel onderwerp (milieu) met een niet-sensationele persoon (politicus) kan toch sensationele aspecten bevatten als de politicus van zeer dichtbij gefotografeerd is, emoties toont, of in zijn huiskamer met de hond knuffelt.

Tenzij anders aangegeven, zijn de variabelen dichotoom (cf. Hendriks Vettehen et al., 2005, 2006; Nuijten, 2007). 'Arousing content' werd gecodeerd wanneer de foto betrekking had op een onderwerp dat appelleert aan overlevingswaarde: criminaliteit en politie, seks, geweld, rampen, oorlog, rellen, opstanden en sport. 'Tabloid packaging' staat voor vormkenmerken die staan voor nieuwigheid of verandering in de omgeving. In deze categorie vallen indicatoren die betrekking hebben op vormgevingsaspecten die de aandacht kunnen trekken: het aantal en de grootte oftewel de relatieve oppervlakte van de foto (relatief aan de totale oppervlakte van de pagina), compilatie (meerdere foto's in of over elkaar geplakt). De laatste variabele is een 'vertaling' van de meting van het aantal shots per scène in onderzoek naar sensatie in televisienieuws. Het oorspronkelijke idee is dat meer shots in een televisienieuwsitem staat voor meer wisseling in stimuli, dat wil zeggen voor 'novelty'. In het geval van kranten kan een compilatie van meerdere foto's als equivalent worden gezien: meer stimuli op de vierkante centimeter. Van deze toepassing is nog niet onderzocht wat het effect op de ontvanger is, zoals bij shots wel het geval is.

Concreetheid werd gemeten met de volgende indicatoren: expliciet getoonde emoties, het voorkomen van 'gewone burgers', personaliseren (human-interestinvalshoek, waarbij mensen in hun eigen levenssfeer getoond worden) en celebrity news. Fysieke nabijheid wordt gesuggereerd door het gebruik van close-ups of een full-faceportret, en een foto uit het eigen land (inclusief de Antillen). Het voorkomen van een expert of politicus werd als indicator genomen voor een niet-sensationeel kenmerk van de foto. Onderzoek heeft aangetoond dat in televisienieuws zogeheten 'talking heads' van politici of experts als abstracte tegenpool van concrete burgers kunnen worden gezien (Edwardson, Grooms \& Proudlove, I98I). Bovendien blijkt uit inhoudsanalyses van televisienieuws dat deze variabele het verwachte 
TABEL 1. Intercodeurbetrouwbaarheid codering per variabele

\begin{tabular}{lll}
\hline & Krippendorffs Alpha & Percentage overeenstemming $^{\mathbf{a}}$ \\
\hline Sensationeel onderwerp & .67 & 94.8 \\
Emoties & .32 & 95.4 \\
Meervoudige foto & .49 & 97.8 \\
Personalisering & .46 & 87.4 \\
Celebrity & .58 & 96.7 \\
Burger & .68 & \\
Expert/politicus & .84 & 93.8 \\
Close-up & .63 & \\
Land & .73 & \\
Portret & .65 & \\
Oppervlakte & .97 & \\
\hline
\end{tabular}

Noot: ${ }^{\text {a }}$ Genomen bij extreem scheve verdeling van coderingen

- aan sensatievariabelen tegengestelde - patroon vertoont (Nuijten, 2007). Dit pleit voor de validiteit van de variabele als indicator voor niet-sensatie.

\section{Betrouwbaarheid}

$\mathrm{Na}$ een drietal trainingsronden hebben drie codeurs onafhankelijk van elkaar een random steekproef dubbel gecodeerd ( $\mathrm{I} 7,5 \%$ van het totale sample). De intercodeursbetrouwbaarheidscores waren over het algemeen bevredigend, hoewel bij een aantal variabelen de betrouwbaarheidsscore zich op de grens van het toelaatbare bevindt (zie tabel I). Toch is om twee redenen besloten deze variabelen mee te nemen in de analyse. Ten eerste zijn in een aantal gevallen de scores van variabelen zeer scheef verdeeld. Gecombineerd met kleine aantallen waarin sommige variabelen voorkwamen is de conservatieve maat Krippendorff's alpha geen goede indicator voor de betrouwbaarheid van de codering (Lombard, Snyder-Duch \& Bracken, 2004; Neuendorf, 2002; Schafraad, 2009). Ten tweede duidt het percentage overeenstemming bij deze variabelen erop dat er wel degelijk een grote mate van overeenstemming bestond tussen de codeurs. Neuendorf (2002) geeft als strenge vuistregel dat de overeenstemming acceptabel is indien die boven de tachtig procent is; bij alle scheef verdeelde variabelen in ons onderzoek is ruimschoots voldaan aan die norm (zie tabel I).

\section{Analyse}

Verschillen tussen de twee typen kranten werden op significantie getoetst door middel van een chi-kwadraattoets, behalve in het geval van continue variabelen, waarvoor een t-toets gebruikt werd. Om een indicatie te krijgen van de mate waarin de 
TABEL 2. Sensatie in Nederlandse krantenfoto's: frequenties en percentages

\begin{tabular}{lll}
\hline & N & $\%$ \\
\hline Aantal foto's & 427 & \\
Sensationeel onderwerp & 280 & 66 \\
Emoties & I44 & 34 \\
Meervoudige foto & II & 3 \\
Personalisering & 79 & I9 \\
Celebrity & 39 & 9 \\
Burger & I6I & 38 \\
Expert/politicus (-) & IO7 & 25 \\
Close-up & IOI & 25 \\
Land $=$ Nederland & 226 & 53 \\
Portret & 73 & I7 \\
& I & SD \\
Aantal foto's per voorpagina & I.93 & I.63 \\
Proportie foto's/totale pagina & 20.8 & 9.5 \\
\hline
\end{tabular}

Noot: $(-)=$ niet-sensationeel kenmerk. Alle percentages zijn afgerond op hele getallen

voorpagina van een krant bepaald wordt door het beeld, is het nodig de verhouding fotoformaat - paginaformaat te berekenen. De mate waarin het oppervlak van de voorpagina's in beslag wordt genomen door foto's is berekend door het aantal vierkante centimeters foto-oppervlak op een pagina te delen door de totale oppervlakte van een pagina.

\section{Resultaten}

We verwachtten dat het grootste deel van de foto's in Nederlandse dagbladen aangemerkt zou kunnen worden als sensationeel. Uit de analyses blijkt dat deze verwachting slechts ten dele uitkomt (zie tabel 2). De belangrijkste variabele is in dit opzicht het in de foto getoonde onderwerp. 66 procent van de foto's, gemeten over alle landelijke kranten, bevat een onderwerp op het gebied van geweld, rampen en ongelukken, criminaliteit en aanverwante zaken. Daarnaast heeft een kleine meerderheid van de foto's betrekking op nabije gebeurtenissen, dat wil zeggen gebeurtenissen in het eigen land. Hoewel we voor de overige indicatoren van sensatie niet kunnen zeggen dat ze in de meeste foto's voorkomen, is wel te stellen dat een aantal sensationele kenmerken zeer regelmatig te zien is op Nederlandse voorpagina's. Een derde bevat emoties en/of de gewone 'man in de straat', terwijl ongeveer een kwart van de foto’s bestaat uit close-ups van gezichten. Daartegenover staat dat politici en andere 
TABEL 3. Sensatie naar type krant: percentages

\begin{tabular}{llll}
\hline & \multicolumn{3}{c}{ Type krant } \\
& Kwaliteit & Populair & $\chi^{2}$ df(1) \\
\hline Sensationeel onderwerp & $69 . \mathrm{I}$ & 63.4 & I.47 \\
Emoties & 24.7 & 39.2 & $9.53^{* * *}$ \\
Meervoudige foto & 0.6 & 3.8 & $3.99^{* *}$ \\
Personalisering & 22.8 & 15.8 & 3.26 \\
Celebrity & 4.9 & II.7 & $5.536^{* *}$ \\
Burger & 46.9 & 32.1 & $9.42^{* * *}$ \\
Expert/politicus (-) & 29.6 & 22.3 & 2.90 \\
Close-up & IO.5 & $3 \mathrm{I} .7$ & $25.248^{* * * *}$ \\
Land = Nederland & $40 . \mathrm{I}$ & 60.8 & $17.18^{* * * *}$ \\
Portret & 5.55 & 24.2 & $24.33^{* * * *}$ \\
& $M(S D)$ & $M(S D)$ & $t$ \\
Aantal foto's per voorpagina & I.22 (.74) & $3.0 \mathrm{I}(1.99)$ & $9.45^{* * * *}$ \\
Proportie foto's/pagina & I9.25(6.5) & $23.20(12.5)$ & $3.072^{* * *}$ \\
$N$ (foto's) & I62 & 265 & \\
\hline
\end{tabular}

Noot: $*<.05 ; * *<.01 ; * * *<.001$ tweezijdig

Noot: (-) = niet-sensationeel kenmerk

hoogwaardigheidsbekleders - die fungeren als indicator voor niet-sensationele kenmerken van een foto - ook op een kwart van de foto's te zien zijn.

Populaire kranten lijken zoals verwacht doorgaans hoger te scoren wat betreft het sensatiegehalte van de foto's. Op acht van de elf kenmerken van sensatie zijn foto's in populaire kranten significant sensationeler dan foto's in kwaliteitskranten (zie tabel 3). Dit geldt echter alleen voor de vormaspecten ('tabloid packaging') en kenmerken van levendigheid ('vividness').

Wat betreft onderwerp zijn er geen verschillen in sensatiegehalte tussen de beide typen kranten. Sterker, als we kijken naar de uitgesplitste onderwerpen die onder het label 'sensationeel onderwerp' vallen, blijkt dat kwaliteitskranten beduidend vaker foto's plaatsen van rampen en ongelukken $\left(\mathrm{Chi}^{2}=\mathrm{I} 2.75, p=.000\right)$ en geweld $\left(\mathrm{Chi}^{2}=\mathrm{I0.05}, p=.002\right)$. Deze contra-intuïtieve bevinding kunnen we verklaren door het feit dat populaire kranten meer foto's met binnenlandse onderwerpen plaatsen dan kwaliteitskranten. Kwaliteitskranten brengen vaker het grote buitenlandse nieuws op de voorpagina; veel van dat grote wereldnieuws bestaat uit oorlogen en rampen. Voor het belangrijkste binnenlandse nieuws geldt dat in mindere mate. Sport is het enige andere onderwerp waarbij we significante verschillen zien; in dit geval plaatsen populaire kranten meer sportfoto's op de voorpagina dan kwaliteitskranten $\left(\mathrm{Chi}^{2}=\mathrm{I} 8.89, p=.000\right)$. 
TABEL 4. Sensatie naar krant: frequenties en percentages

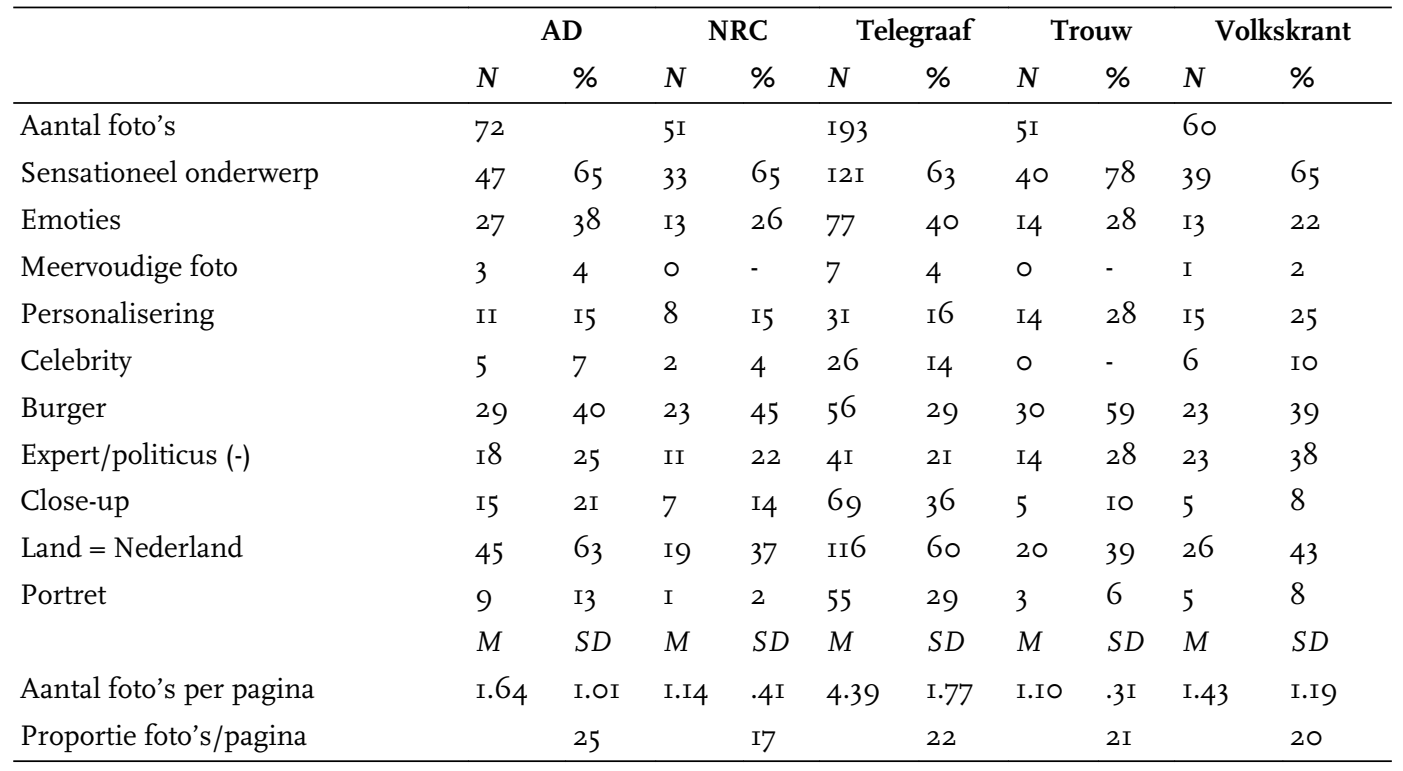

Noot: $(-)=$ niet-sensationeel kenmerk. Alle percentages zijn afgerond i.v.m. leesbaarheid

Het aantal foto's op de voorpagina's van populaire kranten is veel hoger dan bij kwaliteitskranten. Hoewel elke individuele foto in populaire kranten gemiddeld kleiner is (M = I34,omm, $S D=\mathrm{I} 49,8)$ dan in kwaliteitskranten $(M=304,7, S D=\mathrm{I} 2 \mathrm{I}, 7, t=$ $\mathrm{I} 2.25, p=.000)$ is de totale oppervlakte van de voorpagina die in beslag genomen wordt door foto's bij populaire kranten daarom hoger dan bij kwaliteitskranten. Opvallend is dat, tegengesteld aan onze hypothese, kwaliteitskranten vaker dan populaire kranten 'de man in de straat', anonieme burgers, op de voorpaginafoto tonen.

Wanneer we de verschillen tussen individuele kranten bezien, kunnen we het bovengeschetste beeld nog wat verder nuanceren (zie tabel 4). Zo zien we dat de populaire krant De Telegraaf het laagste percentage foto's met een sensationeel onderwerp bevat (maar wel verreweg de meeste foto's in totaal heeft), terwijl het kwaliteitsdagblad Trouw met 78 procent op dit kenmerk de meest sensationele foto's bevat. De verschillen zijn echter relatief klein $\left(\mathrm{Chi}^{2}=4.45, p=.035\right)$. Ook is er een duidelijk verschil tussen de twee populaire kranten: De Telegraaf plaatst gemiddeld meer foto's per voorpagina dan Algemeen Dagblad $(t=8.95, p=.000)$. Wat betreft de verschillen in het oppervlak van de pagina dat in beslag genomen wordt door foto's, kunnen we een vergelijkbare nuancering aanbrengen. De twee populaire dagbladen Algemeen Dagblad en De Telegraaf verschillen zoals verwacht niet significant van 
elkaar op dit aspect. Ook de kwaliteitsbladen NRC Handelsblad, de Volkskrant en Trouw verschillen onderling niet, met uitzondering van NRC Handelsblad versus Trouw ( $t=-3.4 \mathrm{I} 6, p=.00 \mathrm{I})$. Maar de verschillen tussen de populaire kranten Algemeen Dagblad en De Telegraaf, en kwaliteitskrant Trouw zijn niet significant ( $t=$ I.332, $p=$. I9, resp. $t=.38 \mathrm{I}, p=.70$ ). Hetzelfde geldt voor De Telegraaf versus de Volkskant ( $t=\mathrm{I} .393, p=. \mathrm{I} 7)$.

\section{Conclusie en discussie}

Onze analyse van het sensatiegehalte van Nederlandse dagbladfoto's levert een vrij genuanceerd beeld op. Als we de voorpaginafoto's op de vijf grootste betaalde dagbladen als indicator nemen, lijkt het wel mee te vallen met het sensatiegehalte van de Nederlandse pers. Ook blijkt dat het niet gemakkelijk is om op basis van het sensatiegehalte van voorpaginafoto's een onderscheid te maken tussen populaire en kwaliteitskranten. Er zijn wel verschillen tussen populaire en kwaliteitsdagbladen, maar de verschillen zijn niet altijd erg groot en eenduidig.

De voornaamste resultaten laten zich als volgt samenvatten. De eerste hypothese wordt ten dele bevestigd: een (kleine) meerderheid van de foto's op de voorpagina's van Nederlandse kranten bevat een sensationeel onderwerp en/of heeft betrekking op een gebeurtenis in eigen land. Wat betreft de vormaspecten is de kwestie minder eenduidig: ongeveer een kwart tot een derde van de foto's is sensationeel te noemen wat betreft een of meer aspecten van vormgeving. Redacteuren lijken een voorkeur te hebben voor foto's die voldoen aan bepaalde kenmerken van geografische (eigen land), fysieke (dichtbij de camera/toeschouwer) en emotionele nabijheid.

De tweede hypothese wordt deels bevestigd. Op acht van de elf kenmerken zijn foto's in populaire kranten significant sensationeler dan die in kwaliteitskranten. Uitzondering is de keuze van het onderwerp: populaire kranten zijn hierin niet sensationeler dan kwaliteitskranten. Kwaliteitskranten plaatsen zelfs vaker (maar niet significant) foto's met rampen en ongelukken en geweld. Ook stellen kwaliteitskranten vaker de 'gewone man' centraal op de voorpaginafoto. Daarnaast zijn er enkele interessante verschillen tussen individuele kranten die ingaan tegen de hypothese.

Kort gezegd zijn populaire kranten vooral 'sensationeler' als het gaat om vormaspecten en levendigheid: ze brengen meer emotie, een dynamischer geheel door elkaar overlappende foto's, de foto's zijn indringender door meer gebruik van closeups en portretten, en ze gaan vaker over binnenlandse onderwerpen. Tevens beslaan de foto's een groter deel van de pagina. Anderzijds geven kwaliteitskranten wat vaker de voorkeur aan ongelukken, rampen en geweld en anonieme burgers. Dit lijkt op het eerste gezicht verrassend, maar heeft te maken met het feit dat kwaliteitskranten vaker kiezen voor onderwerpen uit het buitenland, en kranten kiezen dan regelmatig voor oorlogen, rampen en onlusten in den vreemde.

Dit onderzoek levert een bescheiden bijdrage aan het debat over het onderscheid tussen populaire en kwaliteitskranten. Veelal wordt dit onderscheid gemaakt op 
impliciet normatieve gronden. Empirisch onderzoek naar het werkelijke bestaan van het onderscheid is schaars. Ook is het zo dat het onderscheid tussen kwaliteitspers en populaire pers in Nederland waarschijnlijk minder duidelijk is dan in landen waarbij er sprake is van een echte 'tabloid press', zoals in het Verenigd Koninkrijk. Dit onderzoek laat echter zien dat er ook in Nederland wel degelijk onderscheid is te maken tussen kwaliteitspers en populaire pers. Populaire kranten verschillen in onderwerpkeuze, zo blijkt uit ander onderzoek (cf. Kleinnijenhuis et al., 2007; Scholten \& Ruigrok, 2006), maar ook in de 'verpakking': foto's in die kranten zijn over het algemeen wat betreft vormaspecten sensationeler. Er is dus aan de hand van deze indicatoren wel degelijk een onderscheid te maken tussen wat in het dagelijks taalgebruik met alle normatieve connotaties de 'populaire' krant en de 'kwaliteitskrant' wordt genoemd. Het onderscheid is echter niet zo zwart-wit als wel eens verondersteld wordt. De verschillen tussen kranten van hetzelfde type (kwaliteit of populair) zijn incidenteel groter dan tussen kranten van verschillende typen.

Het is opvallend te noemen dat, hoewel het merendeel van de foto's een sensationeel onderwerp bevat, populaire en kwaliteitskranten even vaak kiezen voor sensationele onderwerpen. Het is niet direct duidelijk wat dat betekent. Sommige auteurs stellen dat de beide typen dagbladen naar elkaar toegroeien in hun onderwerpkeuze (cf. Connel, I998). Maar in dit onderzoek lijkt de verklaring ergens anders te liggen. Het lijkt erop dat kwaliteitskranten vaker kiezen voor onderwerpen als oorlog en onlusten in het buitenland, terwijl populaire kranten liever kiezen voor onderwerpen van dichtbij. Daardoor scoren kwaliteitskranten hoger op onderwerpen als geweld en rampen, en niet omdat ze steeds meer kiezen voor dezelfde onderwerpen als populaire kranten. Integendeel, ze kiezen expliciet vaker voor foto's uit het buitenland.

Dit onderzoek is een van de eerste waarin een kwantitatieve analyse van het sensatiegehalte van krantenfoto's is gedaan (een uitzondering in ons taalgebied is Hauttekeete, 2005) en naar ons beste weten het eerste waarin de kwaliteitspers wordt vergeleken met populaire pers op het sensatiegehalte van foto's. Onze resultaten nuanceren het idee van velen - onder andere uit onderzoek naar buitenlandse kranten (Djupsund \& Carlson, I998; Uribe \& Gunter, 2004) - dat het met het sensatiegehalte in het nieuws de spuigaten uitloopt. Hoewel we zien dat een (soms substantieel) deel van de foto's op de voorpagina's een of meer sensationele kenmerken bevat, is niet zo duidelijk te stellen dat de Nederlandse dagbladfoto over het algemeen sensationeel is. Anders gezegd, fotoredacteuren kiezen regelmatig voor een foto met een sensationeel kenmerk, maar niet per definitie en niet vaak met meerdere sensationele kenmerken tegelijk (bijvoorbeeld zowel emoties als geweld in een foto).

In tegenstelling tot wat vaak verondersteld wordt, is sensatie in het nieuws niet per definitie een slechte zaak. In televisienieuws kan een gezonde dosis sensatie - dat wil zeggen een dosis die niet de zintuigen lamlegt - er zelfs voor zorgen dat de aandacht en intensiteit van de kijker bij het verwerken van informatie stijgt, met een verbeterde herinnering van informatie tot gevolg (Grabe et al., 2000; 2003). Foto's 
met sensationele kenmerken hebben de potentie om de aandacht te trekken naar (belangrijke) nieuwsberichten en die aandacht langer vast te houden dan bij artikelen zonder foto of met een niet-sensationele foto (Knobloch et al., 2003; Zillmann et al., 200I). Anderzijds is in onderzoek naar sensatie in televisienieuws herhaaldelijk aangetoond dat sensatie ook kan leiden tot een 'cognitive overload' die juist leidt tot vermijdingsgedrag van het brein. Herinnering en begrip van de informatie zijn daardoor navenant. Geniet, maar met mate is dus het idioom.

Daarmee raken we ook aan een ander punt: mogelijk is het label 'sensatie' niet het meest gelukkige. Hoewel 'sensation' en 'tabloidization' gebruikt worden als labels in de internationale onderzoeksliteratuur waarin van dezelfde operationalisaties gebruik wordt gemaakt als hier, en hoewel deze labels inmiddels geaccepteerd lijken te zijn geraakt, gaat het in feite om 'automatische aandachttrekkers': kenmerken van een mediaboodschap die altijd en overal de aandachts- en opwindingscentra van het menselijk brein activeren. 'Sensatie' daarentegen heeft in het maatschappelijk debat vooral negatieve connotaties met geweld, bloed, opgeklopte verhalen, et cetera. Veel van deze aspecten komen in het hier gebruikte concept overigens aan bod, maar het blijft de vraag of de vlag de lading helemaal dekt. Een ander punt van mogelijke kritiek op de studie is de lage intercodeurbetrouwbaarheid van sommige variabelen. Hoewel we beargumenteerd hebben waarom deze variabelen toch in onze studie werden meegenomen, verdient het de voorkeur om te voldoen aan de geijkte toetsen. Een grotere steekproef waarbij ook voor weinig voorkomende variabelen voldoende spreiding gegarandeerd is, kan dit euvel wellicht verhelpen.

Tot slot moet er enige voorzichtigheid worden betracht bij de interpretatie van onze analyses vanwege de steekproef. Hoewel de maanden september tot november vaker gebruikt worden als steekproefperiode vanwege het feit dat seizoensinvloeden klein zijn, en er in ons geval geen grote sportevenementen, verkiezingen of andere grote nieuwsgebeurtenissen waren die afwijken van een 'normale' nieuwsperiode, zou een andere steekproeftrekking - bijvoorbeeld een geconstrueerde week (Riffe, Lacy \& Fico, 2005) - nog beter zijn geweest. Daarnaast betreft het hier geen trendstudie, waardoor we geen beeld hebben van ontwikkelingen in de tijd, of van de oorzaken van het voorkomen van sensatie (zoals organisationele doelen, concurrentiesterkte, technologische ontwikkelingen, etc.). Toekomstig onderzoek naar sensatie in de pers zou zich dan ook op deze aspecten moeten richten.

\section{Literatuur}

Adams, W.C. (1978). Local public affairs content on TV news. Journalism Quarterly, 55(4), 690-695.

Bakker, P., \& Scholten, O. (2006). Communicatiekaart van Nederland: Overzicht van media en communicatie (derde druk). Alphen aan den Rijn: Kluwer.

Broersma, M. (2003). Tegen de trend: Regionale journalistiek in een veranderende samenleving. Apeldoorn: Wegener.

Bucy, E.P. \& Bradley, S.D. (2004). A social-biological perspective on the news. Paper presented at the $54^{\text {th }}$ annual ICA Conference, 27-3I May, 2004, New Orleans, USA. 
CEBUCO/SummoScanner (I992). Bereikscijfers Summo-Scanner; Jaarrapport tweede halfjaar I99I t/m eerste halfjaar i992. Amsterdam: CEBUCO

Coleman, R. (2006). The effects of visuals on ethical reasoning: What's a photograph worth to journalists making moral decisions? Journalism Q Mass Communication Quarterly, 83(4), 835-850

Connel, I. (I998). Mistaken identities: Tabloid and broadsheet news discourse. Javnost/The public, 5, II-3I.

Davis, H., \& McLeod, S L. (2003). Why humans value sensational news: An evolutionary perspective. Evolution and Human Behavior, 24, 208-216.

Djupsund, G., \& Carlson, T. (I998). Trivial stories and fancy pictures? Tabloidization tendencies in Finnish and Swedish regional and national newspapers I982-I997. Nordicom Review, 19(I), IOI-II4.

Edwardson, M., Grooms, D., \& Proudlove, S. (I98I). Television news information gain from interesting video vs. talking heads. Journal of Broadcasting, 25(I), I5-24.

Esser, F. (I999). 'Tabloidization' of news: A comparative analysis of Anglo-American and German press journalism. European Journal of Communication, 14, 29I-324.

Garcia, M.R., \& Stark, P. (I99I). Eyes on the news: St Petersburg: Poynter Institute.

Grabe, M.E., Zhou, Z., Lang, A., \& Bolls, P.D. (2000). Packaging television news: The effects of tabloid on information processing and evaluative responses. Journal of Broadcasting and Electronic Media, $44(4), 58 \mathrm{I}-598$.

Grabe, M.E., Lang, A., \& Zhao, X. (2003). News content and form: Implications for memory and audience evaluations. Communication Research, 30(4), 387-413.

Grabe, M.E., Zhou, S., \& Barnett, B. (200I). Explicating sensationalism in television news: Content and the bells and whistles of form. Journal of Broadcasting \& Electronic Media, 45(4), 635-655.

Graber, D.A. (I994). The infotainment quotient in routine television news: A director's perspective. Discourse Q Society, 5, 483-508.

Hauttekeete, L. (2005). De tabloidisering van kranten: mythe of feit? De ontwikkeling van een meetinstrumenten en een onderzoek naar de tabloidisering van Vlaamse kranten. Gent: Universiteit Gent.

Hendriks Vettehen, P., \& Nuijten, K. (2006). In need of an audience: Sensationalism in Dutch Public Service news and current affairs programs in the I990s. Paper presented at the 3 rd Bi-annual RIPE conference, I6-I8 November, 2006, Hilversum and Amsterdam.

Hendriks Vettehen, P., Nuijten, K., \& Beentjes, J. (2005). News in an age of competition: The case of sensationalism in Dutch television news, I995-200I. Journal of Broadcasting \& Electronic Media, 49, 282-295.

Hjarvard, S. (2000). Proximity: The Name of the ratings game. Nordicom Review, 21(2), 63-8I.

Hoof, A.M.J, van (2000). Kranten met karakter: Identiteit van kranten vanuit kwaliteitsperspectief. Amsterdam: Thela Thesis.

Huysmans, F., De Haan, J., \& Van den Broek, A. (2005). Achter de schermen: Een kwart eeuw lezen, luisteren, kijken en internetten. Den Haag: SCP.

Hvitfelt, H. (I994). The commercialization of the evening news. Changes in narrative technique in Swedish TV news. Nordicom Review, 15(I), 33-4I.

Jansen, C.H. (I987). Dagblad en politiek. Muiderberg: Coutinho.

Kleemans, M. Van Cauwenberge, A., d'Haenens, L., \& Hendriks Vettehen, P. (2008). Op zoek naar verklaringen voor sensatie in het nieuws: Een vergelijking tussen Nederlandse, Vlaamse, Waalse en Franse televisiejournaals. Tijdschrift voor Communicatiewetenschap, 36(4), 30I-3I9.

Kleinnijenhuis, J., Oegema, D., Ridder, J. De, \& Hoof, A. van (2007). A test of rivaling hypotheses to explain news effects: News on issue positions of parties, real world developments, support and criticism and success and failure. Journal of Communication, 57, 366-384.

Knobloch, S., Hastall, M., Zillmann, D., \& Callison, C. (2003). Imagery effects on the selective reading of internet newsmagazines. Communication Research, 30(3), 3-29.

Lang, A. (2000). The limited capacity model of mediated message processing. Journal of Communication, $50(\mathrm{I}), 46-47$.

Lewis, J., Andrews, W., \& Franklin, B. (2008). Four rumours and an explanation: A political economic account of journalists' changing newsgathering and reporting practices. Journalism Practice, 2, 27-45. 
Lindhout, I., \& van Praag, P. (2000). Dagbladen: Sfeer en interpretatie. In P. van Praag \& K. Brants (red.), Tussen beeld en inhoud: Politiek en media in de verkiezingen van 1998 (pp. 86-III). Amsterdam: Het Spinhuis.

Lombard, M., Snyder-Duch, J., \& Bracken, C. (2002). Content analysis in mass communication. Assessment and reporting of intercoder reliability. Human Communication Research, 28, 587-604.

Manssens, J., \& Walgrave, S. (I998). Populair en/of kwaliteit? De Vlaamse pers over de zaak Dutroux. PSW papers. Wilrijk: Departement Sociale en Politieke Wetenschappen.

McManus, J. (I994). Market-Driven journalism: Let the citizen beware? Thousand Oaks: Sage.

McManus, J. (2009). The commercialization of news. In K. Wahl-Jorgensen \& T. Hanitzsch (eds.) The handbook of journalism studies (pp. 218-235). New York: Routledge.

Neuendorf, K.A. (2002). The content analysis guidebook. Thousand Oaks: Sage.

Newhagen, J.E. (I998). TV news images that induce anger, fear, and disgust: Effects on approach-avoidance and memory. Journal of Broadcasting \& Electronic Media, 2(2), $265-276$.

NOM (2008). Doelgroep monitor 2008-2. Amsterdam: NOM.

Nuijten, K. (2007). Sensatie in het Nederlandse televisienieuws 1980-2004. Nijmegen: Radboud Universiteit.

Ohlemacher, T. (I996). Medien und Gewalt. Bild in der Zeit des ausländerfeindlicher Gewalttaten. In H-G. Heiland \& C. Lüdemann (eds.), Soziologische Dimensionen des Rechtsextremismus (pp. I37-I59). Opladen: Westdeutsche Verlag.

Outing, S. (2004). Eyetrack III: What news websites look like through the readers' eyes. http:// www.poynter.org/content/content_view.asp?id=70472, geraadpleegd op I6 december 2009 .

Pew Research Center for the People and the Press (2008). Audience segments in a changing news environment: Key audiences now blend online and traditional sources. Washington DC: Pew.

Plasser, F., \& Ulram, P.A. (2003). Striking a responsive chord: Mass media and right-wing populism in Austria. In G. Mazzoleni, J. Steward \& B. Horsfield (eds.), The media and neopopulism. A contemporary comparative analysis (pp. 2I-43). Westport: Praeger.

Raeymaeckers, K. (2002). Young people and patterns of time consumption in relation to print media. European Journal of Communication, 17, 369-383.

Riffe, D., Lacy, S., \& Fico, F.G. (2005). Analyzing media messages: Using quantitative content analysis in research ( $2^{\text {nd }}$ ed.).Mahwah, NJ: Lawrence Erlbaum.

Shoemaker, P.J. (I996). Hardwired for news: Using biological and cultural evolution to explain the surveillance function. Journal of Communication, 46 (3), 32-47.

Schafraad, P. (2009). Controversial outsiders: A cross-national study of media attention to the far right. Dissertatie, Radboud Universiteit Nijmegen.

Scholten, O., \& Ruigrok, N. (2006). Politiek en politici in het nieuws in vijf landelijke dagbladen. De Nederlandse nieuwsmonitor. Amsterdam: Stichting het Persinstituut.

Schönbach, K., Lauf, E., McLeod, J.M., \& Scheufele, D.A. (I999). Distinction and integration: Sociodemographic determinants of newspaper reading in the USA and Germany, I974-96. European Journal of Communication, I4, 225-239.

Slattery, K.L., \& Hakanen, E.A. (I994) Sensationalism versus public affairs content in local television news: Pennsylvania revisited. Journal of Broadcasting \& Electronic Media, 38, 205-216.

Tai, Z., \& Chang, T. K. (2002). The global news and the pictures in their heads: A comparative analysis of audience interest, editor perceptions and newspaper coverage. Gazette, 64(3), 25I-265).

Uribe, R., \& Gunter, B. (2004). The tabloidization of British tabloids. European Journal of Communication, 19(3), 387-402.

Zillmann, D., Knobloch, S., Yu, H. (200I). Effects of photographs on the selective reading of news reports. Media Pyschology, 3, 30I-324. 